Robert J. Byrick, MD FRCPC, J. Colin Kay, AINLT, J. Brendan M. Mullen, MD FRCPC

\title{
Pulmonary marrow embolism: a dog model simulating dual component cemented arthroplasty
}

The cardiopulmonary changes resulting from cemented arthroplasty procedures were monitored in 11 dogs with a single prosthesis implanted and nine dogs with a dual arthroplasty procedire. These changes were characterized by decreased $B P$, elevuted $P P_{A}$, and elevated $P V R$, associated with decreases in $\mathrm{PaO}_{2}$, cardiac output and mixed venous oxggen tension. All changes were more pronounced and protonged in the dual component arthroplasty group. Histologic lung examination and morphometry demonstrated significant degrees of marrow (fat) microembolism in the duat arthroplasty model. Cardiopulmonary collapse has been associated with Guepar dual component arthroplasties clinically and these patients are at increased risk and should be monitored continuously. Prophylactic mensures include meticulous lavage of the intramedullary cavity, increased $\mathrm{FrO}_{2}$, and mainuenance of intravascuiar volume and cardiac output. The bilateral arthroplasty model is useful in investigating therapeutic interventions which may detect and prevent the marrow microembolism syndrome intraoperatively.

\section{Key words}

SURGERY: orthopaedic, arthroplasty; cOMPLICATIONS: martow embolism, hypoxaemia; LUNG: marrow embolism, hypoxaemia.

From the Department of Anaesthesia, University of Toronto, St. Michacl's Hospital, and the Department of Pathology, Mt. Sinai Hospital (JBMM), Toronto, Ontario.

Address correspondence to: Dr. R. J. Byrick, Department of Anaesthesia, St. Michael's Hospital, 30 Bond Street, Toronto, Ontario, M5B IW8.
Hypoxaemia and cardiovascular collapse leading to cardiac arrest rarely ${ }^{1}$ complicate single component cemented arthroplasty procedures. Less catastrophic cardiopulmonary dysfunction occurs more commonly ${ }^{2,3}$ and has been attributed to pulmonary microembolism by the contents of the intramedullary cavity, ${ }^{4,5}$ absorbed monomer, and air emboli. We have reported a dog model which simulates a single leg cemented arthroplasty procedure. ${ }^{6}$ This model documented transient increases in pulmonary artery pressure and pulmonary vascular resistance, and small decreases in systemic arterial oxygen transport following a single cemented prosthesis insertion. ${ }^{6.7}$.

The purpose of this study was to evaluate the cardiopulmonary changes resulting from insertion of bilateral cemented prostheses as compared to the single prosthesis model reported previously. ${ }^{6.7}$ Simultancous insertion of two long-stemmed cemented implants theoretically doubles the potential for marrow embolism and, clinically, has been associated with a higher incidence of cardiovascular collapse. ${ }^{8}$ By using two legs in this animal study, we hoped to induce a more severe lung lesion which could be used to study various prophylactic and therapeutic interventions.

\section{Methods}

Twenty mongrel dogs weighing $19.5-38 \mathrm{~kg}$ were anaesthetized with pentobarbitone $30 \mathrm{mg} \cdot \mathrm{kg}^{-1}$ IV followed by a continuous infusion of pentobarbitone $5 \mathrm{mg} \cdot \mathrm{kg}^{-1} \cdot \mathrm{hr}^{-1} \mathrm{IV}$. The tracheas were intubated and the lungs mechanically ventilated with a non-rebreathing circuit using room air. Ventilation was adjusted to produce a tidal volume of $15-20 \mathrm{ml} \cdot \mathrm{kg}^{-1}$ at a rate of $6-9$ breaths $\cdot \mathrm{min}^{-1}$ to keep arterial $\mathrm{PCO}_{2}\left(\mathrm{PaCO}_{2}\right)$ at $35-40 \mathrm{mmHg}(4.65-5.32 \mathrm{kPa})$. Lactated Ringer's soiution, approximately $10 \mathrm{ml} \cdot \mathrm{kg}^{-1}$. $\mathbf{h r}^{-1}$ was administered IV.

A 7 Fr. triple-lumen balloon tipped pulmonary artery catheter was inserted into the left femoral vein and positioned in the pulmonary artery to continuously measure pressure (PPA). Thermodilution cardiac output (Q) 
was measured in triplicate using an Edwards Laboratory Model 9510 cardiac output computer. The mean value of $\dot{Q}$ was used at each measurement period. The left femoral artery was cannulated to measure systemic arterial blood pressure (BP). A Cordis 7 Fr. pigtail catheter was inserted into the left carotid artery and advanced retrogradely through the left ventricle to the left atrium to monitor pressure (PLA).

Samples of arterial and mixed venous blood (from the pulmonary artery catheter) were obtained for blood gas analysis and all values corrected for body temperature. Mixed expired gases were collected using a one-way valve attached to the endotracheal tube, and analyzed for oxygen and carbon dioxide concentration. Intrapulmonary shunt fraction $(\mathrm{Q} / \mathrm{Qt})$ and the ratio of physiological deadspace to tidal volume ( $\left.V_{D} / V_{T}\right)$ were calculated using standard equations.

The operative procedure utilized a lateral parapatellar exposure of the distal femur with dislocation of the patella medially. The femoral canal was drilled and reamed retrogradely to a depth of $10 \mathrm{~cm}$, using successively larger reamers (Pohl-Howmedica) until a size nine reamer was readily inserted. Zimmer low-viscosity bone cement was then injected under manual pressure and a solid, contoured metal prosthesis was hammered into the femoral intramedullary canal.

In 11 dogs (single-component group) only onc femur was used for prosthesis insertion. In nine dogs (bilateralcomponent group) both femora were simultaneously reamed and bilateral cemented arthroplasties were performed. Control measurements were recorded after exposure of either one or both femora in the respective groups and measurements repeated at 5, 15, 30 and $60 \mathrm{~min}$ following implant insertion. Arterial pressure, pulmonary artery pressure and left atrial pressure were recorded continuously.

While still anaesthetized, the dogs were kil]ed by injecting potassium chloride though the left atrial line. In the bilateral-component group, the chest was opened immediately and the pulmonary vessels ligated. The heart and lungs were removed en bloc. The lungs were fixed in inflation with ten per cent buffered formalin at a pressure of $25 \mathrm{~cm} \mathrm{H}_{2} \mathrm{O}$. After fixation for 72 hours the lungs were sectioned sagitally and three stratified random blocks of known size were taken from the mid-sagittal slice of each lung. Samples were post-fixed in Flemming's solution for 72 hours followed by washing in running water for 24 hours. Samples were processed for histological examination in the usual manner, then cut at five micron thickness. Morphometric measurements were performed on the six lung specimens from each dog using a camera lucida and an IBM-PC computer assisted digitizing board. The number of fat emboli from 12 random fields from each of

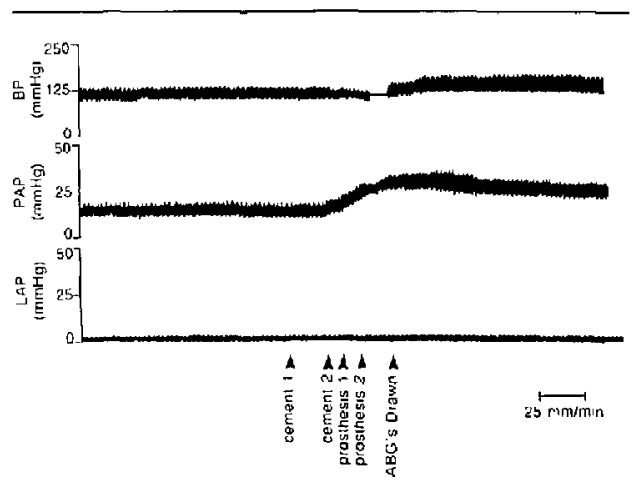

FIGURE I A representative trace of the pressures measured continuously during cement and prosthesis insertion in one dog.

the six lung specimens in each dog were determined for a total lung area of $72 \mathrm{~mm}^{2}$ per animal.

All femora used in the study were removed and radiographically examined to verify prosthesis location, and absence of fracture.

Mean values are reported plus or minus one standard error of the mean. Differences between control and post-implant values were analyzed using a two-way analysis of variance and Dunnett's multiple range test. Differences between groups were analyzed using Student's unpaired t test. When $p<0.05$, the differences were considered significant.

\section{Results}

Figure 1 shows a typical recording during a bilateral component arthroplasty procedurc. There were no significant differences noted in the mean weight of dogs (26.4 and $26.1 \mathrm{~kg}$ ) or control arterial blood gas values between groups.

The haemodynamic changes at 5-, 15-, 30- and 60 -minute intervals after cement and prosthesis insertion are noted in Figure 2. No significant BP change was noted in the dogs after a single implant was inserted; however, in the bilateral arthroplasty group, significant hypotension was present at 5 and 15 minutes after insertion. The decrease in BP was significantly greater in the bilateralcomponent group $(\mathrm{p}<0.05$ ) than the single leg group at 5-, 15- and 30-minute intervals. Cardiac output decreased significantly in both groups (Figure 3), without any change in $P \overline{L_{A}}$ (Figure 2). There was no significant difference in cardiac output at any measurement period between groups. Significant increases in PिA (Figure 2) and calculated pulmonary vascular resistance (PVR) (Figure 3) were found in both groups which persisted throughout the 60-minute follow-up. The increases in P $\overline{P A}$ 


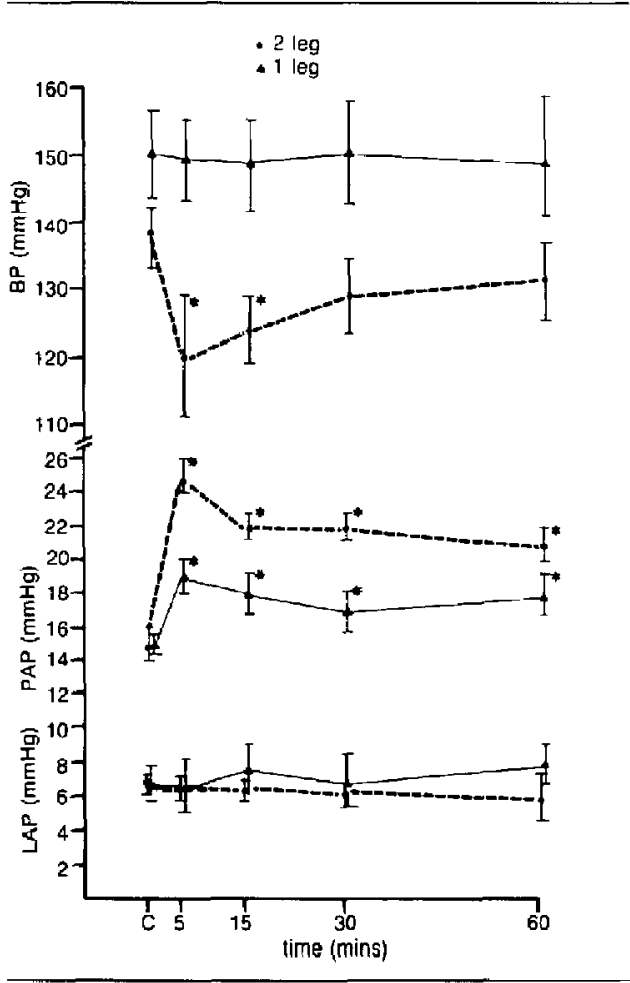

FIGURE 2 Mean ( \pm SEM) values for anerial blood pressurc (BP), pulmonary artery pressure (PAP) and left atrial pressure (LAP) prior to cement and prosthesis insertion (C) and at $5,15,30$ and 60 minutes after arthroplasty procedure in each group. "Indicates statistically significant difference from control (C) value.

and PVR were significantly greater $(p<0.01)$ in the bilateral-component group at every measurement period after cement and prosthesis insertion. $\overline{P A}$ and PVR increased in every animal studied in both groups.

Figure 4 depicts the gas exchange data obtained in each group. A statistically significant but small decrease in measured arterial oxygen tension $\left(\mathrm{PaO}_{2}\right)$ occurred only at the five-minute measurement in the single-component group. However, a larger decrease in $\mathrm{PaO}_{2}$ was noted in the bilateral-component group at all measurement periods, which was maximal at 15 minutes after cement and prosthesis insertion. Arterial oxygen saturation $\left(\mathrm{O}_{2}\right.$ sat) decreased significantly only in the bilateral-component group. This decrease in mean atterial $\mathrm{O}_{2}$ saturation was small (approximaately two per cent) but was statistically significant at all measurements after prosthesis insertion and was significantly greater $(p<0.05)$ in the bilateralcomponent group.
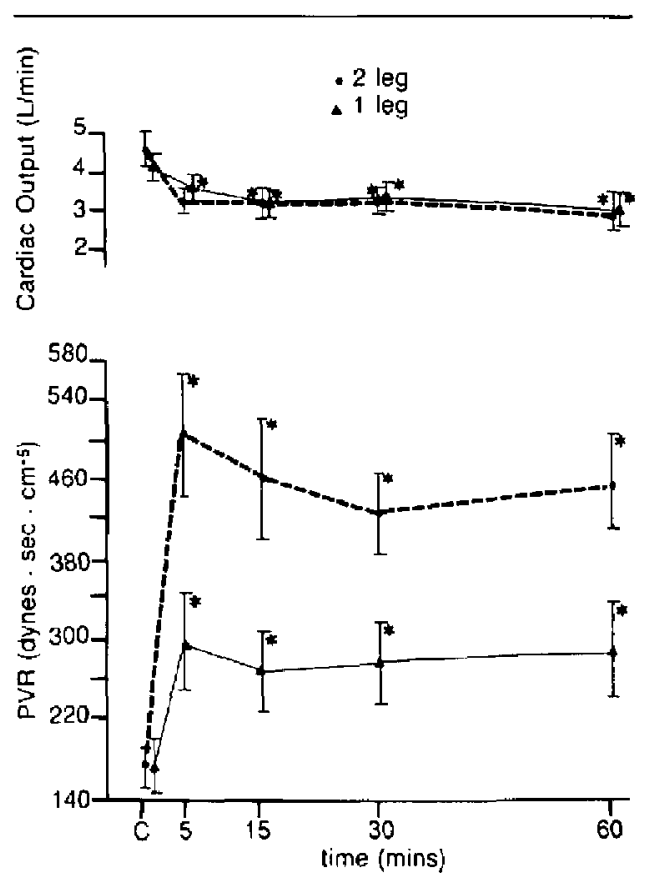

FIGURE 3 Mean ( \pm SEM) values of cardiac output and calculated pulmonary vascular resistance (PVR) prior to cement and prosthesis insertion (C) and at 5-, 15-, 30- and 60-minute intervals after arthroplasty procedure in each group. *Indicates statistically significant difference from control (C) value.

No significant change in $\mathrm{VD}_{\mathrm{D}} / \mathrm{VT}, \mathrm{Qs} / \mathrm{Qt}$, oxygen consumption or $\mathrm{PaCO}_{2}$ were noted in either group (Table). A significant decrease in mean mixed venous oxygen tension $\left(\mathrm{PrO}_{2}\right)$ was detected only in the bilateral component group (Figure 4) and this decreased $\mathrm{PvO}_{2}$ remained significantly lower than the control value throughout the study period. Statistically significant decrease in the haemoglobin oxygen saturation of mixed venous blood $\left(\mathrm{SvO}_{2}\right)$ was noted after cemented prosthesis insertion in both groups. These decreases were larger in the bilateral component group. No significant difference in the change in $\mathrm{SvO}_{2}$ or $\mathrm{P}_{\overline{\mathrm{O}}} \mathrm{O}_{2}$ between groups was found (Table).

Radiographic examination as well as direct inspection of all bones after the experiment showed no fractures and no significant difference in the size of the bones used between groups.

The mean percentage of lung volume occupied by fat cmboli in each of 72 random fields from each animal specimen was $2.10 \pm 1.16$ per cent. The size of vessel occluded by fat microemboli on quantitative morphometric study of the lung is shown in Figure 5. Ninety-three 


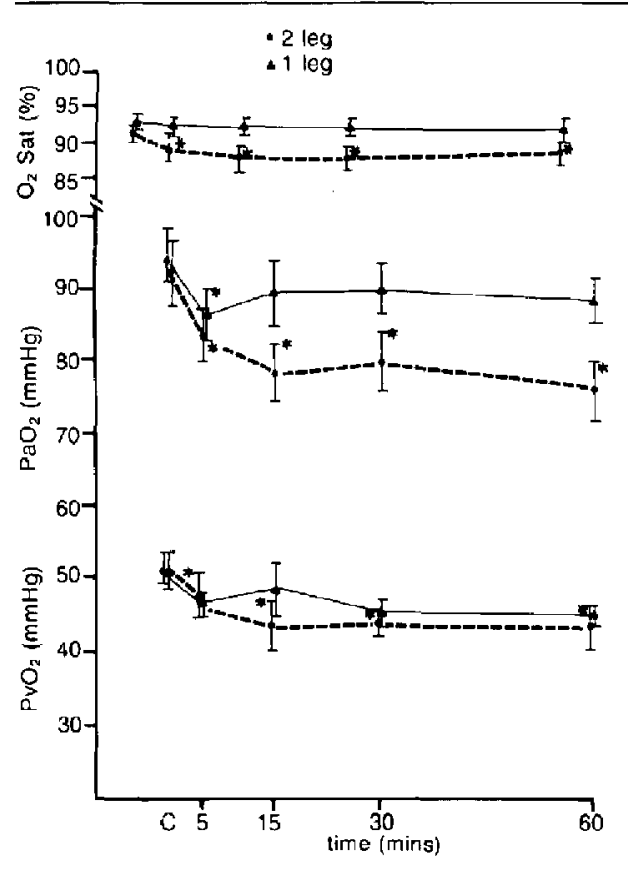

FIGURE 4 Mean ( \pm SEM) of measured axygen tension $\left(\mathrm{PaO}_{2}\right)$ and haemoglobin saturation $\left(\mathrm{O}_{2}\right.$ sat $)$ in arterial blood samples and mixed venous oxygen tension $\left(\mathrm{PuO}_{2}\right)$ at the contro! measurenent (C) and $5,10,30$ and 60 minutes after cement and prosthes is insertion.

per cent of emboli were in capillaries less than 50 microns in diameter.

\section{Discussion}

Kallos ${ }^{4}$ documented transient hypoxaemia in patients following prosthesis insertion and suggested that transient decreases in $\mathrm{PaO}_{2}$ are frequently undetected by conventional monitoring techniques. Clinical experience ${ }^{1,2}$ suggests that catastrophic cardiovascular collapse during cemented arthroplasty procedures is accompanied by a prolonged period of pulmonary hypertension and elevated pulmonary vascular resistance. Since no animal in either group developed profound hypotension or cardiac arrest, catastropic marrow embolism syndrome ${ }^{1,2}$ may represent a more severe form of a common, sublethal pathological process, which is analogous to our model.

Both the degree and the duration of the cardiovascular and gas exchange abnormalities (Figures 2, 3 and 4) in this study were greater with the bilateral arthroplasty procedure. This suggests that the prime determinant of the extent of cardiopulmonary dysfunction may be the

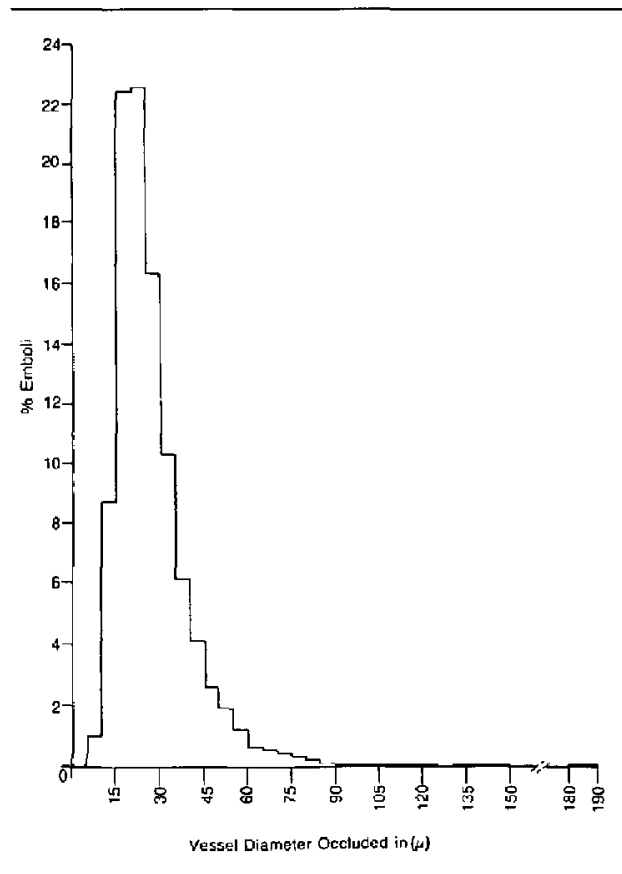

FIGURE 5 Histogram showing the percentage of emboli found in pulmonary vesscls of various diameters of the bilateral arthroplasty group

embolic load resulting from pressurization ${ }^{5}$ of the reamed intramedullary canal during cement and prosthesis insertion. ${ }^{9}$ The single-component model resulted in no hypo. tension and small, very transient decreases in $\mathrm{PaO}_{2}$. The bilateral-component model produced significant decreases in BP (Figure 2) and significantly greater increases in $\overline{P A}$ and PVR. Although the mean $\mathrm{PaO}_{2}$ only fell to $78.9 \pm 11.2 \mathrm{mmHg}$, several animals in this group demonstrated significant oxygen desaturation of haemoglobin (minimal $\mathrm{O}_{2}$ sat $=84$ per cent). The reduced $\mathrm{PaO}_{2}$ was significantly different from control (Figure 4) at all mcasurement times in the bilateral arthroplasty group. This pattern of elevated $\overline{P A}$ and PVR with decreased $\mathrm{PaO}_{2}$ is similar to clinical reports in patients. ${ }^{1-4}$

Kay and Noble ${ }^{10}$ found that gas exchange abnormalities after repeated small embolic loads were smaller than if the same number of starch microemboli were given as a single bolus. Our data suggest that the physiologic mechanism for the immediate hypoxaemia after cement and prosthesis insertion may not be increased intrapulmonary shunting, as Qs/Qt did not change significantly in either group (Table). In this animal model, the immediate decrease in $\mathrm{PaO}_{2}$ of the bilateral arthroplasty group 
TABLE Changes from control values in intrapulmonary shunt fraction (Qs'Qt), physiological deaspace/tidal yolume ratio $\left(\mathrm{V}_{\mathrm{D}} / \mathrm{VT}\right)$, arterial $\mathrm{PCO}_{2}\left(\mathrm{PaCO}_{2}\right), \mathrm{O}_{2}$ consumption $\left(\mathrm{O}_{2}\right.$ cons.) and haemoglobin oxygen saturation of mixed venous blood $\left(S \mathrm{SV}_{1}\right)$ in single and bilateral component groups (Mean $\left.\pm S F M\right)$

\begin{tabular}{|c|c|c|c|c|c|}
\hline $\begin{array}{l}\text { Time after } \\
\text { prosthesis } \\
\text { insertion }\end{array}$ & $\Delta Q_{s} Q t$ & $\Delta V_{D} / \mathrm{T}$ & $\triangle \mathrm{PaCO}_{2}$ & $\mathrm{AO}_{2}$ cons. & $\triangle \mathrm{S}^{\mathrm{N}} \mathrm{O}_{2}$ \\
\hline \multicolumn{6}{|l|}{5 minutes } \\
\hline Single & $2.37 \pm 1.54$ & $-0.79 \pm 1.28$ & $-0.49 \pm 0.92$ & $4.97 \pm 4.46$ & $-3.78 \pm 1.55$ \\
\hline Bilateral & $1.88 \pm 1.32$ & $2.14 \pm 0.86$ & $-0.10 \pm 0.54$ & $-4.47 \pm 6.65$ & $-4.19 \pm 1.89$ \\
\hline \multicolumn{6}{|c|}{15 minutes } \\
\hline Single & $0.52 \pm 1.17$ & $-1.93 \pm 1.09$ & $-1.02 \pm 0.81$ & $2.91 \pm 4.45$ & $-4.88 \pm 1.66$ \\
\hline Bilateral & $2.51 \pm 1.49$ & $0.45 \pm 0.86$ & $-2.11 \pm 0.53$ & $0.71 \pm 6.01$ & $-6.74 \pm 1.74$ \\
\hline \multicolumn{6}{|l|}{30 minutes } \\
\hline Single & $-0.95 \pm 1.39$ & $-0.78 \pm 1.55$ & $-0.97 \pm 1.05$ & $0.82 \pm 4.65$ & $-4.98 \pm 1.64$ \\
\hline Bilatcral & $1.78 \pm 0.82$ & $-0.39 \pm 1.22$ & $0.14 \pm 1.19$ & $1.95 \pm 4.19$ & $-6.74 \pm 1.89$ \\
\hline \multicolumn{6}{|c|}{60 minutes } \\
\hline single & $-0.08 \pm 1.38$ & $-0.74 \pm 1.48$ & $-1.04 \pm 1.34$ & $2.66 \pm 4.68$ & $-4.88 \pm 1.65$ \\
\hline bilateral & $0.94 \pm 1.72$ & $0.53 \pm 1.39$ & $0.43 \pm 1.22$ & $-6.80 \pm 4.44$ & $-6.41 \pm 1.91$ \\
\hline
\end{tabular}

appeared to be related to a reduced $\mathrm{P}_{\overline{\mathrm{O}}} \mathrm{O}_{2}$ and $\mathrm{Q}$ (Figures 3 and 4). The late effects of marrow embolism on intrapulmonary shunt and pulmonary function remain conjectural, and pulmonary oedema with elevated Qs/Qt may be a factor later in the course of the syndrome. Histological cxamination did not reveal evidence of pulmonary cedema 60 minutes after cement and prosthesis insertion in the bilateral component model which had the largest

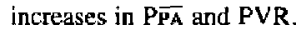

The control measurements in this study were made prior to reaming of the intramedullary canal(s), approximately 15 minutes before cement insertion. One concern was that the reaming process itself might contribute to the marrow embolism syndrome. In other studies, ${ }^{6,9}$ we have shown no significant cardiopulmonary changes with reaming alone. Pathological examination of one dog's lung after reaming revealed only $0.07 \mathrm{vol} \%$ of lung tissue occluded (unpublished data). This is three per cent of the amount of embolic material found in this study after the bilateral arthroplasty procedure ( $2.10 \pm 1.16$ per cent). The size of vessels occluded (Figure 5) are very similar to those occluded in one patient dying of the catastrophic marrow embolism syndrome." This strongly suggests that the physiologic as well as pathological lung changes in our model are similar to those found in clinical practice.

Data from the Guepar group ${ }^{8}$ suggest that dual component cemented procedures have a very high incidence of cardiovascular collapse (14/103). Our study and clinical experience ${ }^{1,2,11}$ suggest that the syndrome of pulmonary hypertension and hypoxaemia is associated with pathological evidence of marrow embolism. By performing two cemented arthroplasty procedures simultaneously, one doubles the potential for marrow embolism. We cannot, however, exclude the role of methylmethacrylate monomer in causing this syndrome as one also doubles the amount of cement inserted. The serum levels of methy]methacrylate monomer after the single-component procedures in this model have been undetectable. 9 The monomer is a known systemic vasodilator when injected intravenously in dogs; ${ }_{1}^{12}$ however, the dose administered in that study was very large. Similarly large doses (2-12 $\mathrm{mg}^{\cdot \mathrm{kg}^{-1}}$ ) given intravenously to sheep have been reported to eause increased lung vascular permeability and elevated pulmonary vascular resistance. ${ }^{13} \mathrm{It}$ is possible that the monomer acts as a systemic vasodilator to accentuate hypotension in the bilateral component model.

Reflex vasoconstriction would be expected as a normal compensatory response to pulmonary embolism and reduced $\dot{Q}$ (Figure 3 ). Breed ${ }^{14}$ has shown that hypotension following cemented arthroplasty procedures is independent of cement and related to the intramedullary pressure generated and hence the number of marrow emboli. We cannot exclude monomer as contributing to the cardiopulmonary instability noted in this model. Left atrial pressure did not change (Figure 2) indicating the absence of left heart failure as a contributing factor to the haemodynamic changes.

There can be little doubt that cemented bilateral component arthroplasty procedures present an increased risk of cardiopulmonary catastrophy ${ }^{\mathbf{1 , 2 , 8}}$ and warrant special anacsthetic consideration. Our study suggests that the rapidity of the onset of the syndrome warrants continuous rather than conventional intermittant monitoring techniques. End-tidal $\mathrm{CO}_{2}$ monitoring and pulse oximetry would seem indicated and, in patients with limited cardiac reserve, invasive haemodynamic monitor- 
ing with a flow-directed pulmonary artery catheter would be valuable. The degree of hypoxaemia resulting from a given embolic load would be greater in patients (or animals) with reduced cardiopulmonary reserve.

Pathologic lung examination and morphometric measurements were performed only on the bilateral arthroplasty group and thus no comparison with the number of marrow emboli in the single-component group was possible. The value of these data is in documenting the presence and size of fat and marrow particles in the lung and the absence of pulmonary oedema or plateletleukocyte microaggregates after 60 minutes of pulmonary hypertension. These pathologic and haemodynamic data suggest an embolic pathophysiologic mechanism accounting for the hypoxaemia after cemented arthroplasty procedures. Data ${ }^{15}$ from a "starch microembolism

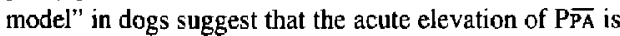
inversely related to survival time, thus severity of lung injury. Does this imply that the elevated PFA and PVR is a result of emboli alone? In our study the total capillary volume of dog lung has been examined using the same morphometric techniques utilized by Siegwart et al. ${ }^{16}$ They estimate that the capillaries account for approximately eight per cent of the total lung volume. ${ }^{16}$ Therefore in our study, where the area occluded was approximately two per cent of total lung volume in the bilateral component group, approximately 25 per cent of the total capillary volume was occluded. This may be an overestimate since capillary distension with elevated $\mathbf{P} \overrightarrow{\mathrm{P}} \mathrm{A}$ would increase the proportion of lung volume occupied by small vessels. Since approximately 50 per cent of total capillary surface area must be oceluded to produce an increase in PPA, ${ }^{17}$ our data suggest that factors other than mechanical obstruction must be involved in the pulmonary hypertension following cemented arthroplasty procedures.

Such factors as tissue thromboplastins, prostaglandin release and other chemical medjators liberated from the reamed contents of the intramedullary canal, or resulting from pulmonary marrow embolism, may be important. ${ }^{18}$ The fat and marrow noted on histological examination may be only markers for these mediators of acute lung injury. Our rcsults indicate that the simultaneous insertion of cemented prostheses into two legs is a better choice than a single leg model for studies investigating the marrow embolism syndrome since it creates a larger sublethal lesion.

If this animal model reflects the clinical syndrome, as our morphometric data (Figure 5) suggests, then the clinician's major emphasis should be to prevent the early physiologic effects of pulmonary microembolism by the contents of the intramedullary cavity. Prevention should focus on meticulous lavage ${ }^{6}$ of the intramedullary canal to evacuate the reamed contents prior to pressurization with cement and prosthesis implantation. Also, non-cemented prostheses may have the advantage of preventing the pressurization ${ }^{9}$ of the intramedullary canal during insertion, as pressure is vented around the prosthesis. Venting of the intramedullary canal with a catheter or drill hole has also been recommended. ${ }^{19,20}$ Thirdly, the efforts of the anaesthetist should focus on preventing hypoxaemia by increasing the inspired oxygen concentration to 100 per cent before prosthesis insertion and the maintenance of cardiovascular stability and cardiac output before and after prosthesis insertion.

\section{Acknowledgements}

The authors wish to thank Zimmer-Bames for providing the cement used. We appreciate the skilled technical assistance of Patricia Slusarenko and Denice Forbes, and the artistic assistance of Susan Lamb, Department of Medical Art, St. Michael's Hospital.

\section{References}

1 Byrick RJ, Forbes $D$, Waddell JP. A monitored cardiovascular collapse during cemented total knee Jeplacement. Anesthesiology 1986; 65: 213-6.

2 Samil $K$, Elmelik E, Goulatier D, Viars $P$. Hemodynamic effects of prosthesis insertion during knee replacement without tourniquet. Anesthesiology 1980; 52: 27I-3.

3 Park WY, Balingir $P$, Kenmore PI, Macnamara TE Changes in arterial oxygen tension during total hip replacement. Anesthesiology 1973; 39: 642-4.

4 Kallos $T$. Impaired arterial oxygenation associated with use of bone cement in the femoral shaft. Anesthesiology 1975; 42: 210-6.

5 Herndon JH, Bechtal CO, Crickenberger DP. Fat embolism during total hip replacement. J Bone Joint Surg 1974; 56-A: 1350-62.

6 Sherman RM, Byrick RJ, Kay JC, Sullivan TR, Waddell $J P$. The role of lavage in preventing hemodynamic and blood gas changes during cemented arthroplasty. I Bone Joint Surg 1983; 65-A: 500-6.

7 Sherman RMP, Waddell JP, Kay JC, Byrick RJ. Large airway response to cemented arthroplasty: relationship 10 hypoxemia. Acta Anaesthesiol Scand 1984; 28: 426-31.

8 Deburge A, Guepar. Guepar Hinge Prosthesis: complications and results with two years follow up. Clin Orthop 1976; 120: 47-53.

9 Orsini EC, Byrick RJ, Mullen JBM, Kay JC, Waddell P Cardiopulmonary function and pulmonary microemboli during cemented and noncemented arthroplasty: the role of intramedullary pressure. (In press) J Bone Joint Surg.

10 Kay JC, Noble WH, Kadiri $Y Z$. Single yersus multiple pulmonary emboli: different haemodynamic and blood gas results. Can Anaesth Soc J 1981; 28: 550-5. 
II Orsini EC, Richards RR, Muilen JMB. Fatal fat embolism during cemented total knee arthroplasty: a case report. Can J Surg 1986; 29: 385-6.

12 Peebles DV, Ellis RH, Stride SD, Simpson BRJ. Cardiovascular effects of methyimethacrylate cement. $\mathrm{Br}$ Med J 1972; 1: 349-51.

13 Fairman RP, Morrow C, Glauser FL. Methylnethacrylate induces pulmonary hypertension and increases lung vascular permeability in sheep. Am Rev Respir Dis 1984 130: 92-5.

14 Breed AL. Experimental production of vascular hypotension and bone marrow and fat embolism with methylmethacrylate cement. Clin Orthop 1974; 102: 227-44.

15 Weisberg $H$, Lopez JF, Luria MH, Katz LN. Persistence of lung oedema and arterial pressure rise in dogs after lung emboli. Am J Physiol 1964; 207: 641-6.

16 Siegwart B, Gekr P, Gil J, Weibel ER. Morphometric estimation of pulmonary diffusion capacity. Respiration Physiology 1971; 13: 141-59.

17 Mclntyre KM, Sasahara AA. The ratio of pulmonary arterial pressure to pulmonary vascular abstruction. Chest 1977; 71: 692-7.

18 Modig J, Busch C, Olerud S, Saldeen T, Waernbaum G. Arterial hypotension and hypoxemia during total hip replacement: the importance of thromboplastic products, fat embolism and acrylic monomers. Acta Anaesthesiol Scand 1975; $19: 28-43$.

19 Engesaeter LR, Strand T, Raugstad TS, Langelano $N$. Effects of a distal venting hole in the femur during total hip replacement. Arch Othrop Trauma Surg 1984; 103: 328-31.

20 Tronzo RG. Kallos $T$, Wyche $M Q$. Elevation of intramedullary pressure when methylmethacrylate is inserted in total hip arthroplasty. J Bone Joint Surg 1974; 56-A: $714-18$,

\section{Résumé}

Les modifications cardiopulmonaires résultant d'arthroplastie avec ciment ont été monitorées chez 11 chiens chez lesquels on avait implantê une prothèse unique et chez neuf chiens chez lesquels on avait procédé à une double arthroplastie. Les changements observés furent: diminution de la PA, augmenfation de la PAP, élévation de la RVP; aussi a-t-on observé une diminution de la $\mathrm{PaO}_{2}$, du débit cardiaque el de la pression veineuse mixte en oxygène. Tous les changements furent plus prononcés et prolongés dans le groupe arthroplastie double. L'histologie et la morphométrie puimonaires ont mis en évidence un degré significarif de microembolie de la moelle (graisse) dans le modèle a" arthroplastie double. En clinique le collapsus cardiovasculaire a été associé à l'arthroplastie en deux compasantes de Guepar et ces patients sont à risque et devraient etre monutorés de fagson continue. Les mesures prophylactiques incluent: le lavage méticuleux de la cavité intramédullaire, une augmentation de la $\mathrm{F}_{1} \mathrm{O}_{2}$, et le maintien du volume intravasculaire et du débit cardiaque. Le modèle $d^{\prime}$ arthoplastie bilatérale est utile dans l'investigation des interventions thérapeutiques qui pourraient dérecter et prévenir le syndrome de microembolie de la moelle en peropérauoire. 